Pnina Ron ${ }^{1}$

Amitay Ron ${ }^{2}$

University of Haifa

\title{
THE RELATIONSHIPS BETWEEN ON-GOING TERROR ATTACKS, MILITARY OPERATIONS AND WARS AND THE WELL-BEING OF JEWISH AND ARAB THREE GENERATIONS CIVILIANS IN ISRAEL
}

\begin{abstract}
Between the state of Israel independent declaration in 1948, until this very days, wars, military operations and on-going national terror had been its daily routine to cope with. The main goal of this study was to review published studies on the impact of those extreme negative life events on the well-being and mental health of various groups of Arab and Jewish civilians in Israel. In addition, this study emphasizes well-known PTSD risk factors related to terrorism, military operations and war in Israel, as well as dissociative symptoms, ASD symptoms, and Death anxiety. The study also deals with some of the background characteristics, the internal and the external resources of the individual, in three age groups, which can take the role of mediator variables between those negative events and the populations' well-being. The literature published in Israel from the beginning of studding those subjects, available up to January 2017, was systematically reviewed. About thirteen studies on the impact of on-going terror attacks and risk factors for distress, trauma and PTSD and, about ten studies on coping strategies were identified. Causes, risk factors, variety of outcomes and coping strategies were widespread from the earlier and traditional to more recent and modern approaches towards those subjects and sometimes integrated.
\end{abstract}

Key words: risk factor, posttraumatic stress disorder, wars, military operations and terrorism, three generations families, Jewish and Arab populations

\section{Introduction}

The main goal of this manuscript is to review existing knowledge on the impact of wars, military operations and terrorism on variety age, gender and ethnicity groups, in Israel. The manuscript attempts to integrate this knowledge regarding those population's mental

\footnotetext{
${ }^{1}$ Ph.D., School of Social Work, University of Haifa, email: pnron@univ.haifa.ac.il

2 Amitay Ron, M.B.A., Faculty of management, strategies human resources management, University of Haifa
} 
health and well-being. It also implements the integrative review approach, combining qualitative and quantitative methodologies (Whittemore, Knafl 2005).

\section{The impact of terrorism, military operations and wars}

Terrorism is defines as the deliberate use of violence or the threat of the use against innocent people with the aim of intimidating them into a course of action that they otherwise would not take (Primoratz 1990). Stern (1999) defines national terror as an act or threat of violence against noncombatants, with the objective of exacting revenge, intimidating, or otherwise influencing an audience. These descriptions highlight the two main characteristics that distinguish terrorism from other forms of violence: first, that it is aimed at noncombatants and thus is different from a conventional war, and second, that violence is used for dramatic purposes, usually to instill fear in the targeted population (Shamai, Ron 2009). The definition of national terrorism suggests some of its consequences for the targeted population: loss of life, injuries and increased anxiety and fear. Studies conducting with victims of direct national terror attacks (i. e., survivors, witnesses and close relatives of those who were killed) confirm that these individuals are at high risk of suffering from a distress reaction (Solomon, Mikulincer, Waysman, Marlowe 1991; Gidron 2002; Shalev, Tuval-Mashiach 2005; Ron, Shamai 2015). The distress symptoms include generalized fear and anxiety, recurrent thoughts about the terror attack, avoidance behavior, physiological symptoms, depression, problems in daily functioning, and difficulties in relating to trusting others. In severe cases, such a distress reaction can result in varying severity levels of posttraumatic stress disorder (PTSD; Solomon, Mikulincer 1991).

Wars and military operations have been a part of the Israeli population's daily experience over the years. Recent examples include the Second Lebanon war (2006), the Cast Lead Operation (2008) and the Protective Edge Operation (2014). The second Lebanon War took place in Israel during summer of 2006 after a kidnapping of three Israeli soldiers and an embracing missiles attack on the Northern border of Israel by the "Hizballah" (the fundamental Islamic party who share political control on Lebanon with Syria and Iran). The Cast Led Operation (2008) was a military operation that took place at the Israeli Southern border as a reaction to the seven years of missiles bombing from the Gaza strip to the Israeli civilians, and the kidnapping of the soldier Gilad Shalit by the "Hamas" and the Palestinian authority (named also the Gaza War). Protective Edge Operation (2014) took place after a kidnapping of three Israeli high school students at the Israeli Southern border with the "Hamas" and the Palestinian authority. By definition, the conditions associated with ongoing missile attacks, military operations and wars entail certain effects on the targeted population (Ron 2014). Despite the fact that the majority of the civilian population suffered neither casualties nor loss of poverty or assets, in almost all of Israel's Northern and Southern communities civilians lives were in real danger and, in fact the entire population in those areas experienced the meaning 
and the impression of war. Emotional changes that stem from an event such as war are affected mainly by the way in which the individual interprets reality and analyzes the likelihood of suffering personal or communal damage. The more threatening the event is perceived to be and the more the individual feels helpless facing the threat, the greater the chances of experiencing an enormous amount of stress and mental trauma. As to the effect of trauma severity, it appears that the greater the exposure, both physically and psychologically, the more evident the expression of mental stress symptoms. It seems that most people are equipped with emotional resilience that allows them to recover quickly after such events and the risk of developing severe mental health problems in response is low (Bonanno, Rennicke, Dekel 2005).

\section{Post-Traumatic Stress Disorder and Acute Stress Disorders and Death Anxiety}

The World Health Organization (2000) claimed that the most common disorders following exposure to a war or a military operation is anxiety and sometimes also depression. Yet, most people do not experience a traumatic event such war in the course of their lifetimes, and only few will develop PTSD. The disorder is characterized by a history of the exposure to extreme mental stress situations that pose a threat to the individual's life, physical health, or to the lives of others (American Psychiatric Association [APA] 2013). Various symptoms can develop as a result of the experience of a traumatic event, among them: nightmares related to the event; avoidance symptoms which include reduced emotions and apathy; symptoms of hypersensitization of the autonomics nervous system, etc. (Ron 2011). When symptoms persist over a period of 1 to 3 months, the possibility of PTSD is considered. Symptoms that persist for more than 3 months and cause severe deficiencies in social and/or professional functioning suggest the condition of chronic PTSD. Nevertheless, exposure to a traumatic event by itself is not a sufficient precondition for subsequent PTSD. The professional literature has demonstrated that only a minority of individuals who were exposure to trauma developed PTSD or other trauma-related disorders (Ozer, Best, Lipsey, Weiss 2003; Johnson, Thompson 2008; Johnson, Maxwell, Galea 2009). Aside from the exposure to the traumatic event, other variables have been examined as PTSD risk factors. These factors are divided into three dimensions: pre-traumatic, peri-traumatic and, post-traumatic. The pre-traumatic variables are viewed as predisposing vulnerability before the traumatic exposure (e.g. history of psychiatric disorder, personality traits), biological and demographic variables etc. (Bomyea, Risbrough, Lang 2012). The peri-traumatic variables are those linked to the actual traumatic event and include the proximity to the event, peri-traumatic dissociation, magnitude of the event, the occurrence of physical injury and its level, and the individual's subjective appraisal of the event (Johnson, Maxwell, Galea 2009; Ozer, Best, Lipsey, Weiss 2003). The stronger predictor of subsequent PTSD was found to be the ASD (Acute Stress Disorders): Manifestation of symptoms 3 days to 1 month after 
the exposure diagnosed as Acute Stress Disorders (American Psychiatric Association 2013). Post-traumatic variables are those characterizing the immediate and duration the individual and his/her surrounding's reaction and coping abilities.

It can be say that in the context of the Northern and Southern Israel's civilians, especially those who live near the borders, chances to be exposed to the prolonged terror threat and to be injured at wars is higher by far than the civilians live in the center of Israel. Researchers view this as a unique type of trauma, prompting abiding civilian hypervigilance, excessive concern, worry, and melancholy. In such circumstances, when an entire population (a city, a village, etc.) is exposed to the same stressor, the social support and the community mental strength may deepen the distress rather than relive it, as social networks can create an environmental effect of heightening fear (Hobfull, London 1986). However, research on the effect of a prolonged terror treats, particularly in Israel, is relatively rare (Laufer, Solomon 2009; Bayer-Topilsky, Itzhaky, Dekel, Mamor 2013), verified after the second Palestinian "Intifada" (the uprising, took held in 2004) that all their research' respondents were exposed to terror attacks either directly or indirectly: $35 \%$ were directly exposed, $66 \%$ were exposed through a family member, and $43 \%$ were exposed through friends. The prolonged terror threat evoked a basic change in the relationships between individuals and their environment, generating a continuous uncertainty in the habits in daily life.

A longitudinal study took place during the Gaza war (2014), included 160 Israeli civilians living in the Southern area of Israel divided into three groups based on proximity to the Gaza strip: (a) lived 4-25 miles from the border; (b) lived 25-50 miles; and (c) lived more than 51 miles away from the border (Gil, Weinberg, Shamai, Ron, Hareland Or-Chen 2015). The study's findings confirm the signicance of ASD symptoms a week after traumatic exposure as the hallmark risk factor for a subsequent development of PTSD at one month. Previous studies showed that approximately $70 \%$ of trauma survivors who initially met criteria for ASD also met criteria for PTSD (Brewin et al. 2000; Franset et al. 2005; Johnson, Maxwell, Galea 2009). Moreover, according to other studies (Van der Kolk, Van der Hart, Marmar 1996; Steuwe, Laniys, Frewen 2012), Gil et al. findings demonstrated the dual effect of dissociation on PTSD. Although immediately after the exposure dissociative symptoms may reduce the risk for PTSD, in the long-run they have the opposite effect-increasing the risk for PTSD significantly. The initial dissociative reacting during and immediately after the traumatic exposure may ease coping with the traumatic nature of the event. Yet, prolonged dissociative symptoms may consolidate to become pathological. Fortunately, geographically proximity to Gaza did not show any association with PTSD. Conceivably, the war condition and the reality that large areas of Israel that were under constant missile attacks, created uncertainty regardless of the variations in distance (Gil et al. 2015).

Death is an inseparable part of the circle of life and as such is a universal natural phenomenon. The literature defended death anxiety as a multidimensional term that relates to death as an accumulation of unpleasant feelings that arise in the individual, such as fear, threat, and emotional discomfort (Neimeyer 1997). Tomer (1992) offers 
a different definition, which considers death anxiety to be experienced on a daily basis and related to mental, physical, and social losses, loss of self and self- fulfillment, loss of control and independence, loss of the body and its deterioration, and the effects of the individual's death on the immediate surroundings.

As war is considered one of the most traumatic and negative events in life for individuals, families, and communities, it has many implications in addition to death, such as long-term physical and psychological damage among children and adults, social and economic deterioration, as well as loss of human and material resources (Murthy, Lakshminarayana 2006) including civil refugees who either are left homeless due to destruction or are fleeing in search of a safe haven (Solomon 1995). The military events referred to herein left most of the civilians living in northern and southern Israel unprotected and exposed to falling missiles. Almost all of Israel's Jewish and Arab civilian communities were in real and immediate danger and, consequently, nearly the entire population experienced the trauma of war and military operation.

The literature suggests that several demographic variables influence the individual's death anxiety and other reactions to events of trauma and stress. Among those variables we can find age, gender, religiosity, as well as intra-personal variables such self-esteem and sense of mastery (Ron 2011; Ron, Shamai 2013; Chung, Preveza, Papandreou, Prevezas 2006; Goenjian et al. 1994).

\section{Age and gender differences}

Death anxiety is more clearly related to age groups: while youths report a high level of death anxiety and the elderly report a relatively low level of anxiety, there is no clear differentiation in the ages between the two extremes (Thorson, Powell 2000). However, as an age group, the elderly experience a lower degree of death anxiety than do the in-between age groups (Fortner, Neimeyer 1999; Azaiza, Ron, Gagini, Shoham 2010).

A major finding of Ron's study (2014) was the significant difference between the levels of PTSD symptoms reported by elderly parents (171 participants between the age 65 and up), their adult children (171 participants in the age of 41-64) and their adult grandchildren (participants in the age of 20-40) in the levels of PTSD symptoms reported. The elderly reported much higher levels of PTSD symptoms than did their adult children. The hypothesis of the study, which predicted that the middle generation of adult children would reported the highest levels of PTSD symptoms, was not confirmed. However, findings similar to those of the current study have demonstrated that the negative effects of war, such as PTSD symptoms, are more common among the elderly population than among the young (Farhood et al. 2006; Tang 2007; Trautman et al. 2002). Farhood and colleagues (2006) explained this finding not in terms of age, but rather in the sheer amount of exposure to number of traumatic events: clearly, the elderly participants have been exposed to more of traumatic events than their offspring. 
Presumably, the extent of exposure to traumatic events, in terms of both number and intensity, played an important role also in the current study as well.

War is a negative event in the life of the individual. It comprises many swift and dramatic changes that require adaptability on the part of the individual. It appears that with age, the individual becomes more vulnerable and less capable of coping with negative life events (Clipp, Elder 1996). These observations help substantiate the findings of Ron's study (2014) and provide an additional explanation for the higher levels of PTSD symptoms found in the elderly group. Another explanation of these findings, which relies on the vulnerability approach mentioned previously, assumes that elderly individuals are more sensitive to the negative effects of traumatic events, such as war, due to accumulated experiences of prior traumas, and as a result they are more vulnerable and less resilient than the individuals in younger generation (Trautman et al. 2002; Dekel, Hobfoll 2007). The elderly population in Israel, mainly - but not only- of the Jewish sector, has experienced many stressful events, including World Wars, the Holocaust, immigration, and Israel's numerous wars and terror attacks. It may be assumed, therefore, that the high levels of PTSD symptoms they reported are related to their initial state of vulnerability, which is greater than that of other younger participants. Moreover, Ron's study (2011), indicated that all participants filled out a questionnaire that examined the influence of previous traumatic events on the individual, including the levels of PTSD symptoms exhibited following those prior occasions. The data collected from the questionnaires of both the elderly parents and their adult children and grandchildren were reviewed, to determine whether prior traumatic experiences might have an accumulative effect on the individual's response to the current trauma. Findings indicated that the elderly participants' higher levels of PTSD symptoms were in fact related to following prior traumatic events and were not exclusively a reaction to the current wars. This finding thus strengthens the claim that the higher levels of PTSD symptoms reported by the elderly participants may be due, at least in part, to these participants' vulnerability following traumatic events experienced prior to this war. To further substantiate this claim, additional research should be conducted, to examine and attain a better understanding of the effects of prior traumatic experiences, and to determine whether such effects are significantly related to the PTSD symptoms exhibited following the current traumatic event.

The lower levels of PTSD symptoms reported by the adult children of the elderly participants can be explained by referring to the significant family role they filled during the war (Ron 2010; 2011). As members of the "sandwiched" generation, during the war they were probably called upon to provide extra support for both their own children and their elderly parents. It is possible that the aid and support that they extended at the time was significant in more than one sense, as this role gave meaning to their own actions and at the same time distracted them, in essence removing them from the sphere of the experience of anxiety and negative feelings, and thus helping them to cope emotionally during wartime. Accordingly, the levels of PTSD reported among members of this generation were lower than those reported by their parents. To strengthen this claim, the issue should be further examined in future studies. 
To conclude, several possible explanations have been presented regarding the differences found in this study between elderly parents and their adult children's responses following the war. To further explore the suggested explanations, these groups should be studied, not only in the aftermath of military operations of war but also in the periods of cessation of military altercations, when the population can return to the routine of their daily lives.

Despite the fact that a higher percentage of men than women are exposed to potentially traumatic events, especially in times of war or military operations, it was found that, regardless of age, women demonstrate a higher degree of psychological vulnerability, they tend to report stressful situations more frequently, they are of greater severity following a traumatic experience, and they develop more incidents of PTSD (Folkman, Lazarus 1980; Silver-Cohen, Holman, McIntosh, Poulin, Gil-Rivas 2002; Farhood, Dimassi, Lehtinen 2006; Bleich et al. 2003). Canetti-Nisim, Mesch, Pedahzur (2006) have found that women reported significantly higher levels of PTS then men did and that the effects of age is an indication of the vulnerability of older adults especially among both Jewish and Arab women and among older Arab men.

Relying on this literature, Ron's hypothesis (2011) was that the female participants will report higher levels of PTSD and the research' findings confirm the hypothesis with the percentage of $19.3 \%$ almost double that was found among the male participants (10\%). Shamai and Kimhi (2007) have conducted a study due to the Israel's withdrawal from Lebanon. Their findings corroborated of previous studies indicating that women experience higher levels of stress compared with men (Aneshensel, Pearlin 1987; Kessler, McRae 1981). Also most of the studies in this field has not dealt with situations of war or threat of terror, which constitute a threat to one's existence, it is possible to compare the findings with those of others studies which have indicated that in severe situations, girls and women have reported higher stress relative to boys and men (Schraedley, Gotlib, Hayward 1999). One way to explain the gender differences is by claiming that the threat of war and terror may push both genders into their traditional roles and limit the flexibility of each. Regarding Israeli teenagers, war-like situations may be associated with army service. Although both genders serve in the army, only men serve in combat roles (Gal 1986). One can assume that socialization processes in Israel prepare boys to be soldiers long before they actually join the army. Soldiers who are exposed to situations of war must control their fearful thoughts and emotions in order to be able to cope with the fighting (Dar, Kimhi 2001). The majority of studies found higher levels of death anxiety among women than among men (Roshdieh, Templer, Cannon, Canfield 1998-1999; Azaiza, Ron, Gagini, Shoham 2010). It is important to note that Ron's study, like many of those which preceded it (Shamai, Kimhi 2007; Ron, Shamai 2013 ), does not clarify whether this finding might be related to women's greater willingness to reveal their emotions or whether it reflects solely a greater vulnerability to traumatic events such as war. 


\section{Ethnicity Differences}

Up until the First Golf War (1991, known also as the "Desert Storm"), and later in the Second Lebanon War (2006) and the Cast Lead Operation (2008), the largest minority group in Israel, namely, the Arab population, had never been part of the population directly subjected to the attack of the countries engaged in confrontation with Israel. Since the establishment of the State of Israel, it had been implicitly understood by both the Israeli government and this minority population that at times of war, this minority population will neither in immediate nor in potential danger, due to the existence of a Pan-Arab alliance. A previous study that made note of an attack against Israel that inadvertently hit the Arab population considered the Second Lebanon War to be the first instance in which Jews and Arabs in Israel shared a frightening and distressing destiny (despite a similar situation during the Al-Aqsa Intifada). The same study also noted the similarly high PTSD levels in the two population groups (Yahav, Cohen 2007; Lavee, Ben-Ari 2003). At the last decade, the Arabs residing in Israel would openly demonstrate their support for the attackers as well as their delight at seeing Israel attacked; however, ever since the frontline has receded into civilian residential areas, they too have experienced the danger, fears and helplessness associated with times of war. As a result, their reactions have become similar to those of the Jewish population (Ron 2014). Indeed, not all of the Arabs living in Israel refer themselves as the Israeli Arabs. As the years go by, more of them refer themselves as Palestinians. However, as the wars accruing in the area became more and more hinterland oriented instead frontline oriented the IsraeliPalestine Arabs shared the same feeling which are describing above. Furthermore, their earlier behavior of "dancing on the roofs" and singing praise songs to Saddam Husain (The Iraqi former dictator), to kill as much Jews as he can in the First Golf War, has been changed and became similar to the Israeli Jewish citizens. They have realized that in times of hinterland war, all citizens are in the same danger for their lives. During the Second Lebanon War, more than $40 \%$ of the casualties (fatal and otherwise) among Israeli citizens were from occurred in Arab cities and villages. The results of the Ron's studies $(2014 ; 2016)$ substantiate these figures, with higher levels of PTSD symptoms reported among non-Jewish participants (Arab Muslims, Arab Christians, and Druze) than among the Jewish participants, as well as a significantly higher rate of possible PTSD diagnosis among the non-Jewish participants compared to the rates among the Jewish participants. These findings are also in line with those of other studies conducted in Israel, which have found that individuals of the Israeli-Palestinians Arab minority experience psychological symptoms and symptoms of depression at higher levels than do their Jewish counterparts, and that they exhibit a higher incidence of possible PTSD diagnosis following traumatic events, compared to the rates found among the Jewish participants (Hobfoll et al. 2008; Yahav, Cohen 2007). Similar to Ron's studies (2014; 2016), Yahav and Cohen found higher levels of Acute Stress Disorder (ASD) among the Arab population after the Second Lebanon War. The explanations they offered for their findings are supported in the current study. Thus, for example, the researchers 
argued that although Arab citizens residing in Israel had been randomly wounded or killed in terror attacks in the past, the Second Lebanon War was the first time that they were not randomly but directly subjected to impending danger. It was also noted that since in the past the residents of Arab villages had always perceived themselves as onlookers from the sidelines, it had never occurred to them that they needed to prepare for the not prepared for prospect of war. Consequently, during the attacks of the Second Lebanon war, there were no shelters or secure rooms available to them. This added to their feelings of helplessness and lack of any sense of mastery, are recognized as crucial protecting resources in traumatic events. The findings in the study of Johnson, Canetti, Palmieri, Galea, Varely, Hobfoll (2009) show that the Arab participants had reported higher levels of PTS and depression symptoms, despite the fact that they were not exposed to terror events as the Jewish participants. The authors suggested that the history of discrimination by the Israeli authority, the ethnic minority attitudes against them, and their empathy with the Palestinian struggle may have it impact on the events on the Arab participants' emotional distress. It should be notice that the history of the Israeli Arabs, who refer themselves as Palestinians, which began in 1948 while they have ranaway or were displaced from the territory which become to be Israel. Apart of them came back after the 48's war but most were and still are considered refugees by the UN. After the 67's war the well-being of those Palestinians decreased more because the experience of living in an unstable environment or facing violence acts of discrimination, persecution and injustice both from the Israeli occupational region and the Arab countries governments (Levav, Al-Krenawi, Ifrah et al. 2007). This history may have its impact on developing vulnerability among the Arab population live in Israel, especially among the elderly people how experienced those events by themselves. Some of those participants may have a part of their family is the Israeli territory and another part in other Arab countries such Jordan, Syria, Egypt or Lebanon. We can assumed that this vulnerability can contribute to development of an ASD, PTSD, and anxiety symptoms because of the wars, the military event etc. mentioned above.

\section{Coping and Well-being}

It appears that some individuals who have been exposed to a traumatic event have reacted by questioning their religious belief system, while in others such an event can serve to strengthen their beliefs, whereby the event is turned into a resource for continued faith (Falsetti, Resick, Joanne 2003; Monahan, Lurie 2007). In addition, it has been suggested that religious conviction in fact prevents the development of PTSD. Studies indicate that "more religious" populations showed less severe signs and fewer symptoms of PTSD than did other groups that were "less" or non-religious (Falsetti et al. 2003; Kaplan, Matar, Kamin, Sadan, Cohen 2005). A study by Green et al. (1990) suggested that the elderly, more than the younger generations, use religion as a resource for contending with distressing situations, which in turn may prevent the development of PTSD. 
In terms of an individual's mental health, studies have found a positive correlation between one's sense of self-esteem and mental health and an inverse correlation between low self-esteem and emotional distress and anxiety (Greenberg et al. 1992; Sumer, Karanci, Berument, Gunes 2005). In addition, it has been claimed that an individual's self-esteem in terms of that person's ability to cope with stress is a factor that affects the development of post traumatic reactions and general mental distress (Benight, Harper 2002).

With regard to traumatized individuals, research strongly suggests that the elderly with either PTSD or subthreshold PTSD suffer grave impairments in daily life and are less satisfied with life (Van Zelst, Beurs, Beekman, Van Dyck, Deeg 2006; Chung, Hunt 2014; Reyes 2014). In addition, growing evidence suggests that perceived benefits following trauma often promote well-being and adjustment (Helgeson, Reynolds, Tomich 2006).

In this context, the ability to withstand extreme traumatic events such as exposure to war may largely depend on the individual's predisposing vulnerability and internal and external resources. Research literature has demonstrated that one of the most important external resources for coping and adjustment is social support (Hobfoll 2002; Lazarus, Folkman 1984). Social support refers to perceived assistance provided by other persons, such as emotional, informational, and tangible assistance (Rosario, Salzinger, Feldman, Ng-Mak 2008). It is a primary interpersonal resource that has been consistently found to be associated with psychological well-being in times of stress, and is generally considered to be a protective factor for individuals who experienced a disaster (Norris et al. 2002), terror attack (Hobfoll, Canetti-Nisim, Johnson 2006; Weinberg 2015), or other potentially life-threatening situations (e.g., Norris, Kaniasty 1996; Shalev et al. 2006). Research indicates that higher levels of social support serve a protective role, and have also been linked to resilience and recovery with respect to traumatic events (Besser, Priel 2010; Gilbar, Plivazky, Gil 2010; King, King, Foy, Keane, Fairbank 1999).

An internal resource that has attracted growing interest among researchers in the field of coping with stressful situations is forgiveness (Chan, Arvey 2011). The notion of forgiveness encompasses cognitive, emotional, and behavioral acts in response to a transgression (Enright, the Human Development Study 1991; Fincham, Kashdan 2004; Witvliet, Phipps, Feldman, Beckham 2004), transforming negative emotions into neutral or positive ones (Thompson et al. 2005). With the expansion of the concept of forgiveness, additional aspects, such as trait forgiveness, which conceptualizes the tendency to forgive across situations and time (Thompson et al. 2005), have been addressed. Multiple dimensions of tendency to forgive, such as situational forgiveness and self-forgiveness, have been identified, demonstrating the positive effect of the tendency to forgive on well-being (Worthington, Witvliet, Pietrini, Miller 2007). Forgiveness has been associated with improvement in mental health, physical health, self-esteem, well-being, and life satisfaction (Bono, McCullough, Root 2008; Harris, Thoresen 2005; Karremans, Van Lange, Ouwerkerk, Kluwer 2003; Toussaint, Webb 2005; Worthington et al. 2007). Research that examined the relationship between traumatic events and tendency to forgive demonstrates an association between tendency to forgive and low PTSD symptoms (Snyder, Hintz 2005; Witvliet et al. 2004; Weinberg, Gil, Gilbar 2013). 


\section{References}

American Psychiatric Association (2000). Diagnostic and Statistical Manual of Mental Disorders ( $4^{\text {th }}$ ed. Text revision). American Psychiatric Association, Washington.

American Psychiatric Association (2013). Diagnostic and Statistical Manual of Mental Disorders ( $5^{\text {th }}$ ed.). American Psychiatric Association, Washington.

Anshensel C.S., Pearlin L.I. (1987). Structural contexts of sex differences in stress, in: R.C. Barnett, L. Biener, G.H. Baruch (eds.), Gender and Stress. Free Press, New York.

Azaiza F., Ron P., Gagini I., Shoham M. (2010). Death and Dying Anxiety among Elderly Arab Muslims in Israel. "Death Studies", 34 (4): 351-364.

Bayer-Topilsky T., Itzhaky H., Dekel H., Mamor Y. (2013). Mental health and posttraumatic growth in civilians exposed to on-going terror. "Journal of Loss and Trauma", 18: 1-21.

Besser A., Priel B. (2010). Personality vulnerability, low social support, and maladaptive cognitive emotion regulation under ongoing exposure to terrorist attacks. "Journal of Social and Clinical Psychology", 29: 166-201.

Bleich A., Gelkopf M., Melamed Y., Solomon Z. (2006). Mental health and resiliency following 44 months of terrorism: A survey of an Israeli national representative sample. "BMC Medicine", 4 (21): 1-11.

Bomyea J.R., Risbrough V., Lang A.J. (2012). A consideration of select pre-trauma factors as key vulnerabilities in PTSD. "Clinical Psychology Review", 32: 630-641.

Brewin C.R., Andrews B., Valentine J.D. (2000). Meta-analysis of risk factors for posttraumatic stress disorder in trauma-exposed adults. "Journal of Consulting and Clinical Psychology", 68: 748-766. Doi: org/10.1037/0022-006X.68.5.748.

Canettii-Nisim D., Mesch G., Pedahzur A. (2006). Victimization from terrorist attacks: Randomness or routine activities?, "Terrorism and Political Violence",18: 485-501.

Chung M.C., Hunt L.J. (2014). Posttraumatic stress symptoms and well-being following relationship dissolution: Past trauma, alexithymia, suppression. "Psychiatric Quarterly", 85 (2): 155-176.

Clipp E.C., Elder G.H. (1996). The aging veteran of World War II: psychiatric and life course insights, in: P.E. Ruskin, J.A. Talbott (eds.), Aging and Posttraumatic Stress Disorder. American Psychiatric Press, Washington: 19-51.

Cohen M. (2008). Acute stress disorder in older, middle-aged and younger adult in reaction to the Second Lebanon war. "International Journal of Geriatric Psychiatry", 23 (1): 34-40.

Dar Y., Kimhi S. (2001). Military service and self-perceived maturation among Israeli youth. "Journal of Youth and Adolescence", 30: 427-448.

Dekel R., Hobfoll S.E. (2007). The impact of resource loss on holocaust survivors facing war and terrorism in Israel. "Aging \& Mental Health", 11 (2): 159-167.

Farhood L., Dimassi H., Lehtinen T. (2006). Exposure to war-related traumatic events, prevalence of PTSD and general psychiatric morbidity in a civilian population from Southern Lebanon. "Journal of Transcultural Nursing”, 17 (4): 333-340.

Frans O., Rimma P.A., Aberg I., Fredrikson M. (2005). Trauma exposure and post-traumatic stress disorder in the general population. "Acta Psychiatrica Scandinavia", 111: 291-299.

Gal R. (1986). A Portrait of the Israeli Soldier. Greenwood Press, New York. 
Gidron Y. (2002). Post-traumatic stress disorder after terrorist attacks: A review. "Journal of Nervous and Mental Disease", 190: 118-121.

Gil S., Weinberg M., Shamai M., Ron P,. Harel H., Or-Chen K. (2015). Risk factors for DSM-5 posttraumatic stress disorder (PTSD) among Israeli civilians during the 2014 Israel-Hamas war. "Psychological Trauma: Theory, Research, and Policy". Doi: org/10.1037/tra0000063.

Helgeson V.S., Reynolds K.A., Tomich P.L. (2006). A meta-analytic review of benefit finding and growth. "Journal of Consulting and Clinical Psychology", 74: 797-816.

Hobfoll S.E., London P. (1986). The relationship of self-concept and social support to emotional distress among women during war. "Journal of Social and Clinical Psychology", 4: 189-203.

Hobfoll S.E. (2002). Social and psychological resources and adaptation. "Review of General Psychology", 6: 307-324.

Hobfoll S.E., Canetti-Nisim D., Johnson R.J., Palmieri P.A., Varley J.D., Galea S. (2008). The association of exposure, risk and resiliency factors with PTSD among Jews and Arabs exposed to repeated acts of terrorism in Israel. "Journal of Traumatic Stress", 21 (1): 9-21.

Johnson R.J., Canetti D., Palmieri P.A., Galea S., Varely J., Hobfoll S.E. (2009). A prospective study of risk and resilience factors associated with posttraumatic stress symptoms and depression symptoms among Jews and Arabs exposed to repeated acts of terrorism in Israel. "Psychological Trauma; Theory, Research, Practice, and Policy", 1 (4): 291-311.

Johnson R J., Maxwell A., Galea S. (2009). The epidemiology of posttraumatic stress disorder. "Psychiatric Annals", 39: 326-334. Doi: org/10.3928/00485713-20090514-01.

Johnson H., Thompson A. (2008). The development and maintenance of post-traumatic stress disorder (PTSD) in civilians' adult survivors of war trauma and torture: A review. "Clinical Psychology Review", 28: 36-47. Doi: org/10.1016/j.cpr.2007.01.017.

Kessler R.C., McRae J.A. Jr. (1981).Trends in the relationship between sex and psychological distress: 1957-1976. "American Sociological Review”, 46: 443-452.

King D.W., King L.A., Foy D.., Keane T.M., Fairbank J.A. (1999). Posttraumatic stress disorder in a national sample of female and male Vietnam veterans: Risk factors, war zone stressors, and resilience-recovery variables. "Journal of Abnormal Psychology", 108 (1): 164-170.

Laufer A., Solomon Z. (2009). Gender differences in PTSD in Israeli youth exposed to terror attacks. “Journal of Interpersonal Violence”, 24: 959-976. Doi.org/10.1177/0886260508319367.

Lavee Y., Ben-Ari A. (2003). Daily stresses and uplifts during times of political tension: Jews and Arabs in Israel. "American Journal of Orthopsychiatry", 73: 65-73.

Levav I., Al-Krenawi A., Ifrah A., Geraisy N., Grinshpoon A., Khwaled R., Levinson D. (2007). Common mental disorder among Arab-Israelis: Findings from the Israel National Health Survey. "Israel Journal of Psychiatry and Related Sciences", 44: 104-113.

Lazarus R., Folkman S. (1984). Stress appraisal and coping. Springer, New York.

Murthy R.S., Lakshminarayana R. (2006). Mental health consequences of war: A brief review of research findings. "World Psychiatry", 5 (1): 25-30.

Neimeyer R.A. (1997). Death anxiety research: The state of the art. "Omega: Journal of Death and Dying", 36 (2): 97-120. 
Norris F.H., Friedman M.J., Watson P.J., Byrne C.M., Diaz E., Kaniasty K. (2002). 60,000 disaster victims speak: Part I. An empirical review of the empirical literature, 1981-2001. "Psychiatry", 65: 207-239.

Ozer E.J., Best S.R., Lipsey T.L., Weiss D.S. (2003). Predictors of posttraumatic stress disorder and symptoms in adults: A meta-analysis. "Psychological Bulletin", 129: 52-73. Doi: org/10.1037/0033-2909. 129.1.52.

Primoratz I. (1990). What is terrorism? "Journal of Applied Philosophy”, 7: 129-138.

Ron P. (2010a). Elderly People's Death and Dying Anxiety: A Comparison between Elderly living within the Community and in Nursing Homes in Israel. "Illness, Crisis \& Loss", 18 (1): 3-17.

Ron P. (2010b). Northern Israeli elderly people's death anxiety after the second Lebanon war, in: N. Nachmias, F. Azaiza, M. Cohen (eds.), Preparedness of health, education, and welfare services to communities under fire: Lesson learned from the Second Lebanon War. Pardes Publication (in Hebrew).

Ron P. (2011). Intergenerational Transmission, Attitudes and Post Traumatic Stress Disorder in Times of War: A Comparison between Elderly People and their adult Offspring after the Second Lebanon War (2006) and Casting Lead Operation (2009)."Illness, Crisis \& Loss", 19 (4): 329-349.

Ron P. (2014). Post-Traumatic Stress Disorder among three generations families in times of war: A Comparison between Israeli Jews and Arabs after the Second Lebanon War (2006) and Casting Lead Operation. “Traumatology”, 20 (4): 269-276. Doi: 10.1037/h0099863.

Ron P. (2016). The relationship between background characteristics and death anxiety in times of war: A comparison between three generations Arab and Jewish families in Israel. "Community Mental Health", Doi: 10.1007/s10597-016-0021-7.

Ron P., Shamai M. (2013). The Impact of Ongoing National Terror on Nurses in Israel. "Community Mental Health", 50 (3): 354-361.Doi: 10.1007/s10597-013-9645-z.

Rosario M., Salzinger S., Feldman R.S., Ng-Mak D.S. (2008). Intervening processes between youths' exposure to community violence and internalizing symptoms over time: The roles of social support and coping. "American Journal of Community Psychology", 41: 43-62.

Schraedley P.K., Gotlib I.H., Hayward C. (1999). Gender differences in correlated of depressive symptoms in adolescents. "Journal of Adolescents Health", 25: 98-108.

Shamai M., Kimhi S. (2007). Teenager's response to threat of war and terror: The impact of gender and social system. "Community Mental Health Journal", 43: 359-374.Doi:10.1300/ J013v43n03_01.

Shamai M., Ron P. (2009). Helping direct and indirect victims of national terror: Experiences of Israeli social workers, “Qualitative Health Research”, 19 (42): 42-54. Doi: 10.1177/1049732308327350.

Shalev A.Y., Tuval-Mashiach R. (2005). Epidemiology of psychological reactions to continuous terror among adults in Israel, in: E. Somer, A. Bleich (eds.), Mental health in terror's shadow: The Israeli experience, (29-54). Ramot Publisher, Tel-Aviv University, Tel-Aviv (Hebrew).

Shalev A.Y., Tuval-Mashiach R., Frenkiel-Fishman S., Hadar H., Eth S. (2006). Psychological responses to continuous terror: A study of two communities in Israel. "American Journal of Psychiatry", 163: 667-673. 
Solomon Z. (1995). Coping with War-induced stress: The Gulf War and Israeli response. Plenum Press, NewYork.

Solomon Z., Mikulincer M. (1991). Monitoring and blunting: Implications for combat-related posttraumatic stress disorder. "Journal of Traumatic Stress", 4: 209-221.

Solomon Z., Mikulincer M., Waysman M., Marlowe D. (1991). Delayed and immediate onset posttraumatic stress disorder: Differential clinical characteristics. "Social Psychiatry and Psychiatric Epidemiology", 26: 1-7.

Stern J. (1999). The ultimate terrorists. Harvard University Press, Cambridge, MA.

Steuwe C., Laninus R.A., Frewen P.A. (2012). Evidence for a dissociative subtype of PTSD by latent profile and confirmatory factor analysis in a civilian's sample. "Depression and Anxiety", 29: 689-700. Doi: org/10.1002/da.21944.

Tomer A. (1992). Death anxiety in adult life - theoretical perspectives. "Death Studies", 16 (6): 475-506.

Van der Kolk B.A., Van der Hart O., Marmar C.R. (1996). Dissociation and information processing in posttraumatic stress disorder, in: B.A. Van der Kolk, A.C. McFartane, L. Weisacth (eds.). Traumatic Stress. Guilford Press, New York, NY.

Van Zelst W.H., de Beurs E., Beekman A.T.F., van Dyck R., Deeg D.D.H. (2006). Well-being, physical functioning, and use of health services in the elderly with PTSD and subthreshold PTSD. "Int. J. Geriat. Psychiatry", 21: 180-188.

Whittemore R., Knafl, K. (2005). The integrative review: Updated methodology. "Journal of Advanced Nursing", 52: 546-553. Doi: 10.1111/j.1365-2648.2005.03621.x.

Yahav R., Cohen M. (2007). Symptoms of acute stress in Jewish and Arab Israeli citizens during the second Lebanon war. "Social Psychiatry and Psychiatric Epidemiology", 42 (10): 830-836. 